\title{
VINTE E UM ANOS DE ATUAÇÃO DO PROJETO DE EXTENSÃO “VAMOS AMAMENTAR, MAMÃE?"
}

\author{
TWENTY-ONE-YEAR EXTENSION PROJECT PERFORMANCE "LET'S \\ BREASTFEEDING, MOMMY?"
}

\begin{abstract}
Marizete Argolo Teixeira ${ }^{1}$, Vanessa Brito Gonçalves ${ }^{1}$, Rosália Teixeira Luz $^{1}$, Vanessa de Matos Araújo ${ }^{2}$
\end{abstract}

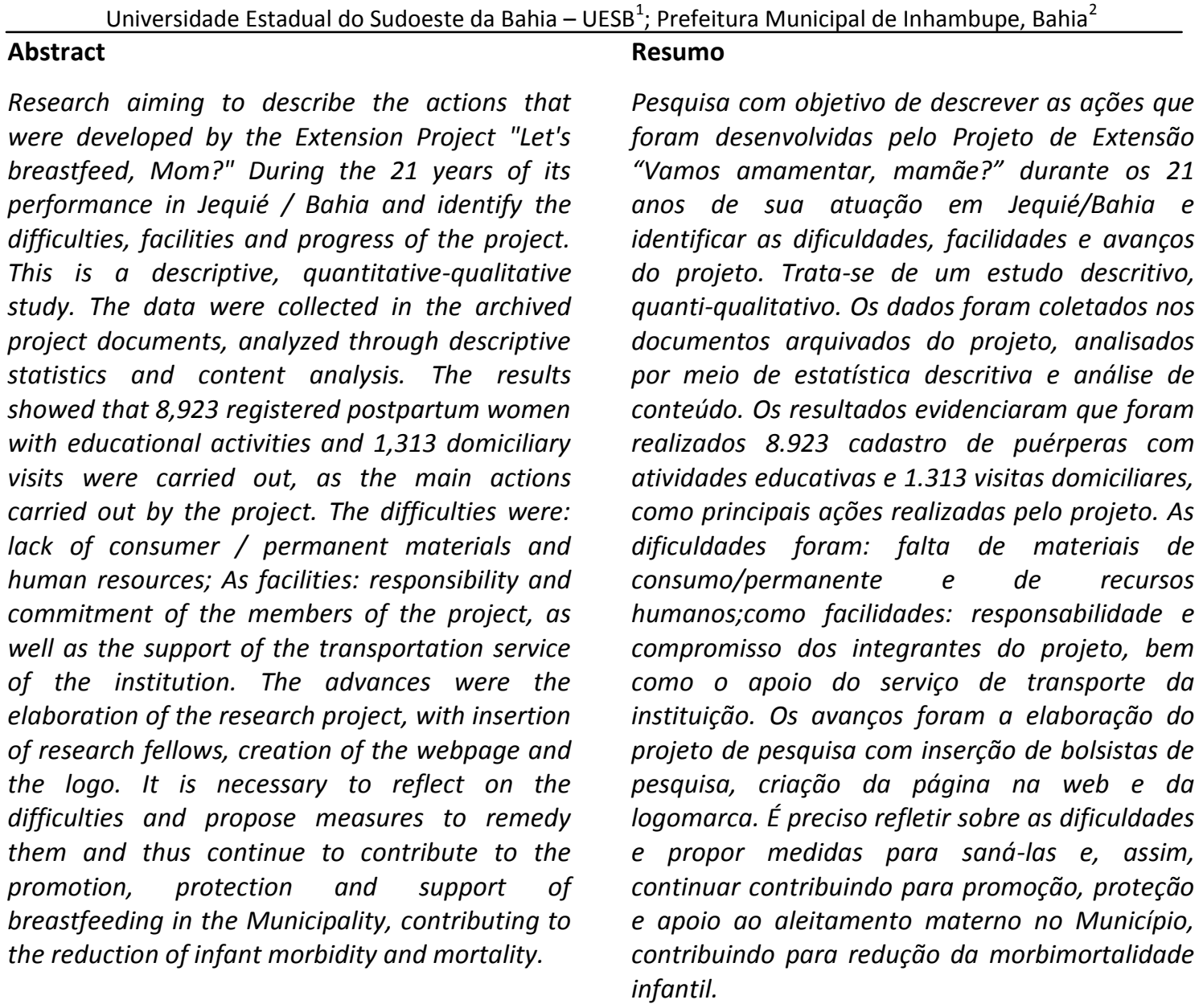

Key words: Breastfeeding. Extension Project. Nursing.
Palavras chave: Aleitamento materno. Projeto de Extensão. Saúde. 


\section{Introdução}

O Projeto de Extensão "Vamos Amamentar, Mamãe?" surgiu em 1993, por iniciativa da docente Joana Angélica Teles Santana, como uma proposta de incentivo ao aleitamento materno na comunidade Jequieense, a ser desenvolvido junto à disciplina Enfermagem Materno Infantil I, do Curso de Graduação em Enfermagem da Universidade Estadual do Sudoeste da Bahia, atualmente denominadas de Enfermagem em Atenção a Saúde da Mulher e Enfermagem em Atenção a Saúde da Criança e do Adolescente.

O ponto inicial para a elaboração e operacionalização do projeto foram as observações efetuadas nos campos clínicos de estágios durante 0 acompanhamento dos discentes pela docente, que observou a pouca importância atribuída ao aleitamento materno pelas puérperas e pelos profissionais de saúde que desenvolviam suas atividades na unidade hospitalar. Além disso, a docente verificou ainda, as dificuldades verbalizadas pelos profissionais da equipe de enfermagem em lidar com as questões que envolvem o aleitamento materno ${ }^{1}$.

o título do projeto além de ser uma pergunta à mulher se a mesma deseja amamentar, sugere um convite e assegura a disponibilidade dos profissionais em ajudá-la, uma vez que sua filosofia parte do pressuposto de que a mulher precisa estar sensibilizada e conscientizada sobre as questões que envolvem a amamentação, para que possa decidir por esta prática. Porém, ela deve ser respeitada em sua decisão, o que exige do profissional de saúde compreensão e conhecimento sobre o manejo clínico da lactação, pois o aleitamento materno embora seja um ato natural, não é meramente instintivo, haja vista que as nutrizes necessitam de apoio, encorajamento e assistência para que possam amamentar seus(suas) filhos(as) com sucesso ${ }^{1,2}$.

O aleitamento materno é considerado como uma das práticas mais eficazes para proporcionar uma alimentação saudável às crianças quando associado a outras medidas de cunho social e econômica, levando á diminuição dos índices de morbimortalidade infantil, um dos motivos que levou o Ministério da Saúde do Brasil (MS) ${ }^{3}$, a Organização Mundial da Saúde (OMS)4 e o Fundo das Nações Unidas para a Infância (UNICEF) ${ }^{5}$, a recomendarem a amamentação exclusiva nos primeiros seis meses de vida e complementado até dois anos ou mais a depender do desejo da nutriz. Sendo assim, o projeto de extensão, visando atingir seus objetivos toma por base os princípios destas organizações.

Portanto, o projeto tem prestado sua parcela de contribuição à comunidade Jequieense e cidades circunvizinhas no que se refere à promoção, proteção e apoio ao aleitamento materno, despertado na comunidade acadêmica e extra acadêmica a necessidade e a importância da amamentação. Desta forma, a Universidade enquanto produtora de conhecimentos, incentivadora do desenvolvimento social, disseminadora de tecnologia e facilitadora da vida da população não poderia se eximir da responsabilidade de desenvolver ações que contribuíssem para aumentar os índices do aleitamento materno em Jequié e demais regiões ${ }^{1}$.

Tendo em vista a importância do projeto durante esses 21 anos junto à comunidade jequieense, verificou-se a necessidade de catalogar dados a partir das ações desenvolvidas a fim de deixar registrados os momentos históricos, com intuito de refletir sobre suas ações e propor outras, caso necessário, para sua melhoria. Além disso, este estudo será de grande importância para os arquivos do projeto, podendo dar visibilidade às ações que vem sendo desenvolvidas pelos docentes, discentes bolsistas e voluntários, mesmo após a saída de sua idealizadora.

Destarte, este estudo tem como objetivos descrever as ações que foram desenvolvidas pelo Projeto de Extensão "Vamos amamentar, mamãe?" durante os 21 anos de sua atuação e identificar as dificuldades, facilidades e avanços do projeto de extensão.

\section{Metodologia}

Trata-se de uma pesquisa descritiva, quantiqualitativa, realizada durante os meses de setembro e outubro de 2014 na Universidade Estadual do Sudoeste da Bahia, a partir do acervo documental do projeto de extensão "Vamos amamentar, mamãe?" arquivados no Núcleo de Pesquisa e Extensão (NUPEX) referentes ao período de 1993 a 2014.

Para iniciar a pesquisa foi solicitado formalmente à coordenadora do Projeto permissão para acessar os documentos existentes. Em seguida, selecionaram-se todos os documentos disponíveis, realizou-se sua catalogação e preencheu-se os formulários elaborados pelas pesquisadoras nas dependências do NUPEX 
Os dados quantitativos foram analisados por meio de estatística descritiva utilizando-se gráficos, tabelas e quadros de frequência gerados em planilha de cálculo Microsoft Excel. A Estatística descritiva é, em geral, utilizada no inicio da análise quando tomamos contato com os dados pela primeira vez, objetivando tirar conclusões de modo informal e direto por meio da observação dos valores colhidos, a fim de resumir os dados para que se tire conclusões e, assim, descrever o que foi desvelado por meio dos mesmos a respeito da temática estudada ${ }^{6}$.

Para os dados qualitativos foi realizado leitura dinâmica dos documentos, buscando identificar as informações que auxiliasse a imersão nos dados não quantificáveis, destacando-se facilidades, dificuldades e avanços enfrentados pelos integrantes do projeto durante os vinte e um anos de sua atuação. O passo seguinte foi realizar leitura atentiva, elencandose os principais resultados e aglutinando-se os semelhantes. A discussão dos resultados foi realizada a partir de estudos que versam sobre a temática.

\section{Resultados e Discussões}

\section{Documentos encontrados}

Os documentos encontrados do projeto de extensão "Vamos amamentar, mamãe?" foram referentes ao período de 1996 a 2014. Sendo eles: cadastramento do projeto, relatórios financeiros e das atividades desenvolvidas durante cada ano, relatórios de visita domiciliar, cadastramento das puérperas que participaram das atividades educativas em grupo e individual, listas de frequência (gestantes e pessoas da comunidade) que participaram das atividades educativas em diversos locais (Unidades Básicas de Saúde, Escolas e Creches), listas de frequência de gestantes que participaram das oficinas sobre amamentação, lista de discentes e profissionais de saúde que participaram de oficinas, treinamentos e capacitações sobre o manejo clínico do aleitamento materno, cartilha educativa e diversos folders desenvolvidos pelos integrantes do projeto, informativos das Semanas Mundiais de Amamentação, livros, textos mimeografados, xerocados, copia do projeto de pesquisa intitulado: o cuidado à família que vivencia o processo de amamentação, lista de frequências das pessoas que participaram das reuniões administrativas e científicas do projeto.

\section{Ações que foram desenvolvidas pelo Projeto de}

\section{Extensão “Vamos amamentar, mamãe?"}

Segundo o registro nos documentos encontrados, durante os 21 anos de atuação, os integrantes do projeto realizaram 8.932 atividades educativas e cadastramento de puérperas em unidades de alojamento conjunto nas clínicas privadas, hospital público e Santa Casa Maternidade São Judas Tadeu, conforme demonstrado na llustração 1.

Os registros das atividades educativas e cadastro de puérperas encontrados foram referentes aos anos de 1996 a 2014, apesar de o projeto ter iniciado suas ações em 1993. Os anos 2004, 2005 e 2007 se destacaram com um percentual maior de atividade educativacadastro de puérpera. Nota-se que nos anos de 1997 e 1999 não foram encontrados registros destas atividades.

Vale destacar que estes registros foram feitos em livros atas até o ano de 2012, momento em que foram implantadas fichas de cadastro elaboradas pelos coordenadores e apreciada pelos demais integrantes do projeto. Os dados coletados dizem respeito ao nome, idade, paridade, data do parto, endereço, ponto de referencia, tipo de parto e assinatura de quem desenvolveu a atividade. Inicialmente, aquelas puérperas que necessitavam de visita domiciliar eram sinalizadas para que os discentes e bolsistas as visitassem no domicílio com intuito de sanar duvidas e ajudar as puérperas e seus famílias durante o início da amamentação.

Vale destacar que em 1996, as atividades educativas-cadastro de puérperas foram realizadas nas diversas clínicas privadas da cidade, já que nesta época os médicos destas instituições realizam um quantitativo significativo de partos. Já nos demais anos, os registros foram centrados na maternidade do Hospital Público e na Santa Casa.

Em 2012 foi implantada a ficha de cadastro de puérpera, tendo sido acrescentado as seguintes questões: Já amamentou? Se sim, quanto tempo? Tem encontrado dificuldades ou facilidades para amamentar? Quais? O que significa a amamentação para a senhora?

A educação em saúde é um dos principais elementos para a promoção da saúde e uma forma de cuidar, proporcionando o desenvolvimento de uma consciência crítica e reflexiva dos sujeitos ao possibilitar a produção de um saber que colabora para que as pessoas possam cuidar de si e de seus familiares ${ }^{7}$. Isso mostra que a educação em saúde está intimamente relacionada com o cuidado e nos 
remete ao duplo papel exercido pelos profissionais de saúde que são também educadores por excelência.

A realização de educação em saúde pelos profissionais deve iniciar desde o pré-natal, devendo acontecer de forma detalhada e melhorada a cada encontro, sendo este processo fundamental para a aquisição de novos conhecimentos, uma vez que, é nessa fase que se inicia o desenvolvimento de vínculo com o novo $\mathrm{ser}^{8}$. No entanto, o período puerperal é um momento importante de se continuar com as ações de promoção, proteção e apoio ao aleitamento materno, cabendo, desta forma, aos profissionais de saúde aproveitar este momento para ajudar o posicionamento, a pega, a ordenha mamária e orientar os cuidados com a mama puerperal, as leis trabalhistas, dentre outras informações.

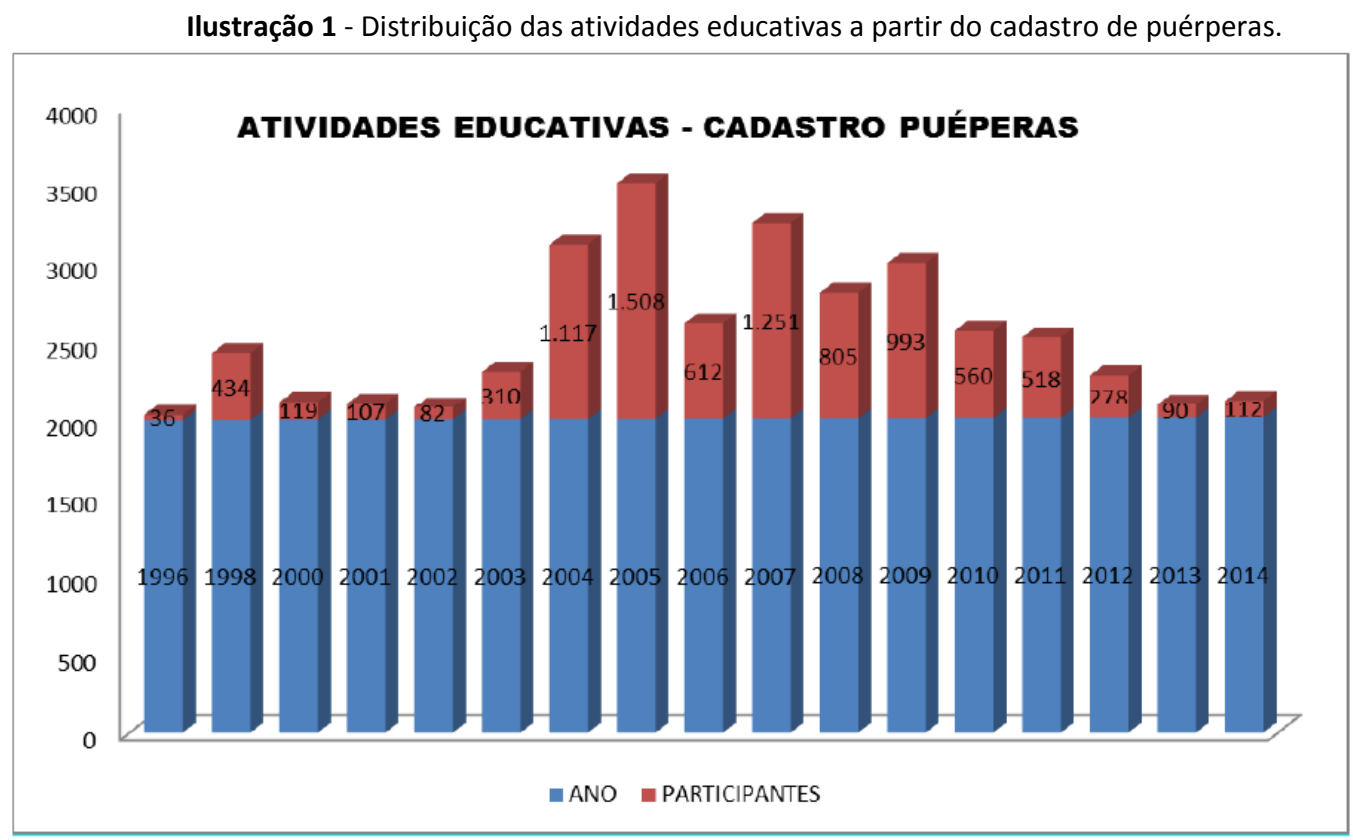

Fonte: Arquivos do Projeto de Extensão “Vamos amamentar, mamãe?”, 2014.

Sobretudo, é no Alojamento Conjunto (AC) que os familiares devem ser acionados, incentivados e orientados a apoiar a mulher que amamenta, pois este é um dos pilares muito importante para ajudar a mulher a iniciar e manter a amamentação, como demonstrado em estudo que relatou a experiência da educação em saúde com puérperas e seus familiares numa maternidade filantrópica. ${ }^{9}$,

No que se refere aos relatórios de visita domiciliar, os dados demonstraram que os integrantes do projeto desenvolveram 1.313 visitas domiciliares, conforme destacado na llustração 2.

Os relatórios de visitas domiciliares encontrados foram referentes aos anos de 2000 a 2014. Com predominância de um quantitativo maior de visitas realizadas nos anos de 2007 e 2008. Os demais anos apresentaram um percentual aquém do desejado. No entanto, vale destacar que foram encontradas 493 fichas de cadastro sem a data da realização da visita domiciliar. Os formulários eram diversos e alguns não continham o campo para anotação da data e, aqueles que continham, não foram especificados pela pessoa que realizou a visita. No ano de 2014, as fichas cadastrais ainda não haviam sido arquivadas, pois se encontravam em mãos dos bolsistas quando da realização da coleta de dados.

Vale ressaltar que nos anos de 1996 e 1997, as visitas realizadas eram destacadas no livro de registro de puérperas cadastradas nas maternidades com uma sigla VD - visita domiciliar. Entretanto, não sabemos se elas foram realmente realizadas e por isso decidimos não computá-las, apesar de sabermos que muitas visitas foram realizadas neste período.

Assim, é importante que o profissional de enfermagem realize visitas domiciliares, não 
Ilustração 2 - Número de relatórios de visita domiciliar.

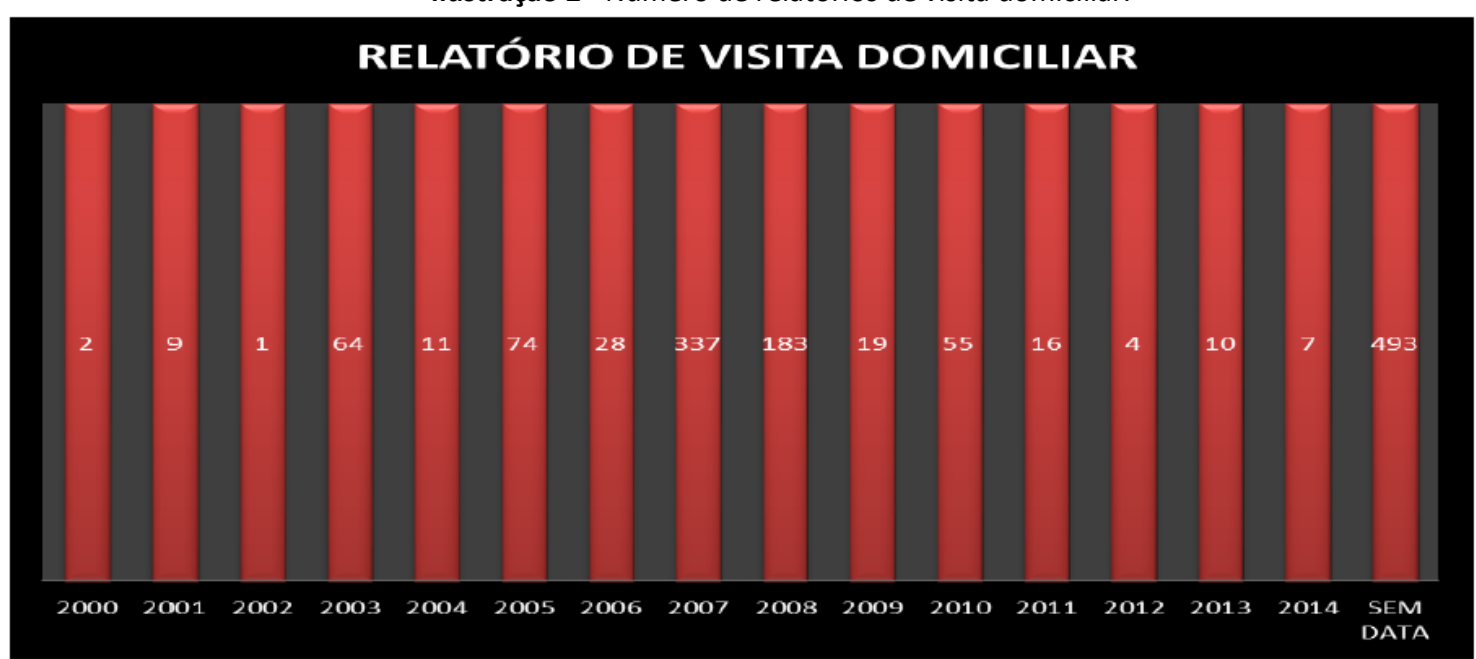

Fonte: Arquivos do Projeto de Extensão “Vamos amamentar, mamãe?”, 2014.

apenas focadas em aspectos do exame físico, a exemplo da verificação da pressão arterial, mas que, próximo à população, crie vínculo profissional/afetivo qualificado, gerador de confiança, para que a população sinta-se à vontade e então partilhe suas dificuldades, angústias, medos e que estes possam ser superados $^{10}$.
No que se refere às palestras realizadas com gestantes, os registros encontrados foram listas de frequência dos participantes, com data, assinatura, local e quem realizou a atividade.

O Quadro 1 apresenta o número de palestras realizadas nos respectivos anos, bem como o número de gestante que participou da atividade.

Quadro 1 -Número de palestras realizadas com gestantes/número de gestantes que participaram da atividade.

\begin{tabular}{|l|l|l|}
\hline ANO & $\mathbf{N}^{\circ}$ PALESTRAS & $\mathbf{N}^{\circ}$ GESTANTES \\
\hline 1995 & 03 & 44 \\
\hline 1996 & 02 & 27 \\
\hline 1997 & 01 & 49 \\
\hline 2005 & 12 & 114 \\
\hline 2006 & 15 & 123 \\
\hline 2008 & 02 & 18 \\
\hline
\end{tabular}

Fonte: Arquivos do Projeto de Extensão “Vamos amamentar, mamãe?”, 2014.

No Quadro 1, é possível observar que muitos anos não apresentaram registros desta atividade. Naqueles que foram encontrados, destacam-se os anos de 2005 e 2006, os quais apresentaram um quantitativo maior de palestras realizadas com gestantes. Estas atividades foram realizadas nas Unidades Básicas de Saúde pelos discentes das disciplinas do Curso de Enfermagem e bolsistas. Vale mencionar que esta atividade sempre foi realizada no projeto apesar da ausência dos registros.

No entanto, a partir de 2008, elas deixaram de ser realizadas devido o número elevado de atividades, poucos integrantes no grupo, em especial docentes. Porém, sabemos que os discentes das disciplinas Enfermagem em Atenção à Saúde da Criança e do Adolescente, Enfermagem em Atenção à Saúde da Mulher e Supervisionado I vem desenvolvendo esta atividade de forma rotineira, entretanto estes registros não estão sendo repassados para a coordenação para serem arquivados no projeto.

As orientações fornecidas à mulher durante o pré-natal são fundamentais para uma gestação saudável, bem como para a manutenção do aleitamento materno. As gestantes, principalmente as primigestas têm inúmeras dúvidas a respeito da importância do 
aleitamento materno, bem como a técnica correta para amamentar, e também as dúvidas pertinentes a mitos e referentes à estética dos seios pós-amamentação. Todos esses pontos são discutidos e difundidos durante as palestras junto aos grupos de gestantes ${ }^{11}$.

No que se refere ao registro das oficinas realizadas em grupos de gestantes organizados em Jequié, merece destacar que esta atividade se mantém desde o inicio do projeto até os dias atuais. Porém, os dados encontrados foram a partir de 1995, inclusive com número maior desta atividade e de participantes, conforme estabelecido na llustração 3.

Jequié conta com vários grupos de gestantes, nos quais sempre foram realizadas

Ilustração 3 - Número de oficinas realizadas nos grupos de gestantes/Número de gestantes que participaram.

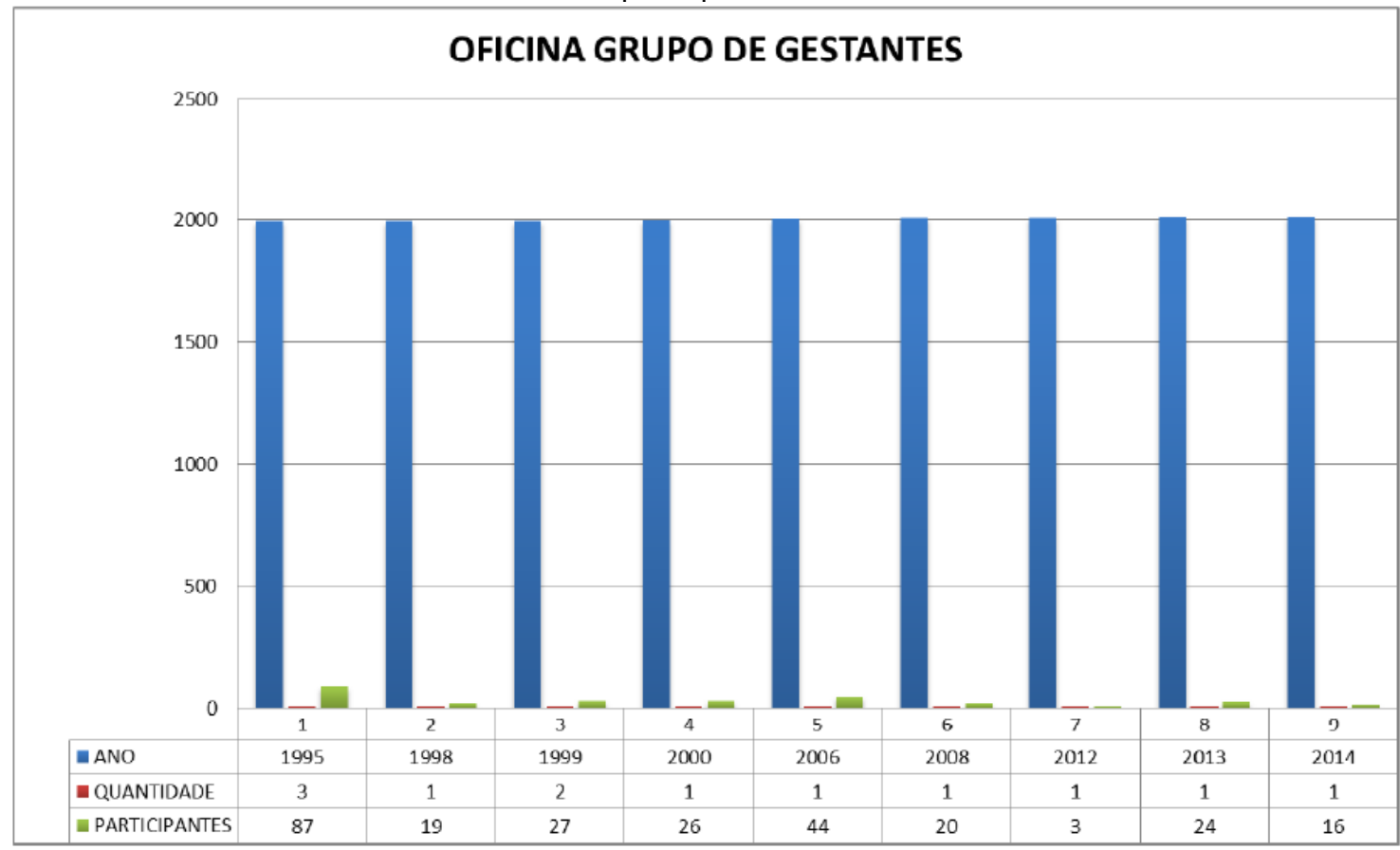

Fonte: Arquivos do Projeto de Extensão “Vamos amamentar, mamãe?”, 2014.

oficinas sobre aleitamento materno pelos integrantes do projeto, seja por coordenadores, colaboradores ou bolsistas e voluntários treinados para o desenvolvimento desta atividade. Os coordenadores dos grupos de gestantes organizados entram em contato com o coordenador do projeto e solicitam a realização da atividade. Os grupos de gestantes, nos quais o projeto vem atuando são: grupo de gestantes da Igreja Matriz e o grupo de Gestante da Creche Santo Antônio. No entanto, também, já foram realizadas atividades em outros grupos de gestantes existentes na cidade.

Uma oficina consiste numa forma de reunir pessoas para discussões, palestras, demonstrações a fim de relacionar a teoria com a prática. No contexto do aleitamento materno auxilia ao desenvolvimento de práticas e técnicas integrativas tanto com puérperas quanto com gestantes, por meio da educação em saúde, a qual propõe um método para produzir conhecimento acerca da saúde às pessoas como proposta estratégica da promoção da saúde ${ }^{12}$.

No estudo desenvolvido por Delfino e seus colaboradores, a partir de oficinas com grupos de gestantes, foi percebido as contribuições trazidas por essa técnica como um meio em que as participantes conseguem compartilhar os seus sentimentos, experiências, afetos, aprendendo de uma forma diferente ao socializar saberes técnico-científico e popular ${ }^{13}$.

Outra atividade desenvolvida pelo projeto diz respeito às palestras na comunidade. A llustração 4 apresenta estes dados.

O gráfico 4 destaca a atuação do projeto no que diz respeito à realização das palestras na comunidade, em especial nas escolas de nível médio e no mês em que se comemora a Semana Mundial de Amamentação (SMAM). Podemos observar que houve um decréscimo quantitativo desta atividade nos anos seguintes. Tal fato ocorreu devido ao surgimento de outras 
atividades que se fizeram necessárias, como as educativas e visitas domiciliares às puérperas, gestantes e seus familiares, com o intuito de fornecer informações pertinentes à prática da amamentação.

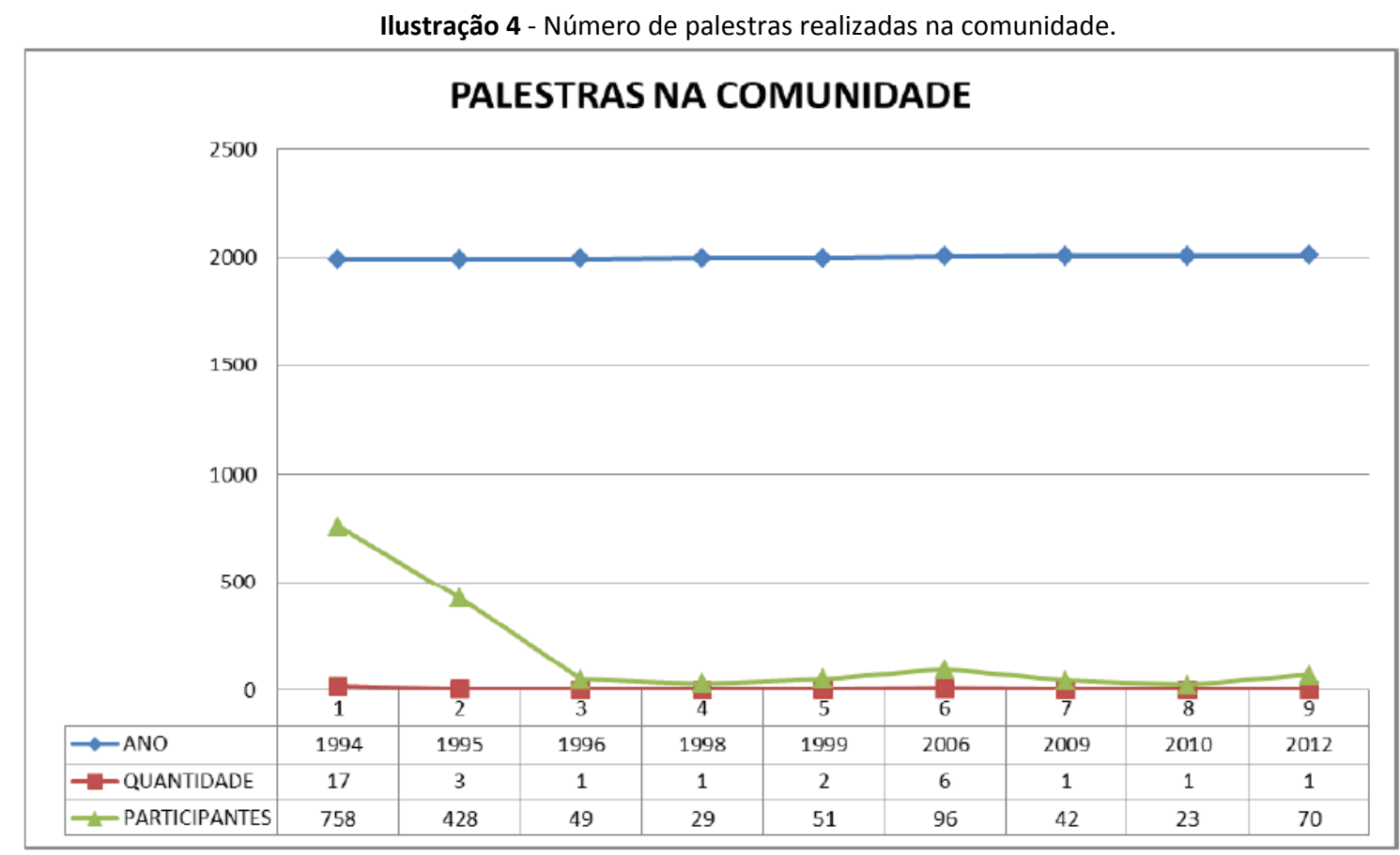

Fonte: Arquivos do Projeto de Extensão “Vamos amamentar, mamãe?”, 2014.

Entretanto, vale salientar que durante a comemoração da SMAM, outras atividades são desenvolvidas, como distribuição de material educativo via correio eletrônico, exposição de mural informativo nas imediações da universidade, de acordo com o tema abordado no ano, entrevistas em radio FM, divulgação no site da instituição e página do projeto na web.
Outra atividade significativa que vem sendo desenvolvida pelos integrantes do projeto e, que merece destaque são as capacitações realizadas, em especial as oficinas com discentes do Curso de Graduação em Enfermagem, do Curso de Técnicos em Enfermagem, dos discentes bolsistas e voluntários do projeto e dos Agentes Comunitários de Saúde, conforme demonstrado na llustração 5 .

llustração 5 - Número de capacitações realizadas.

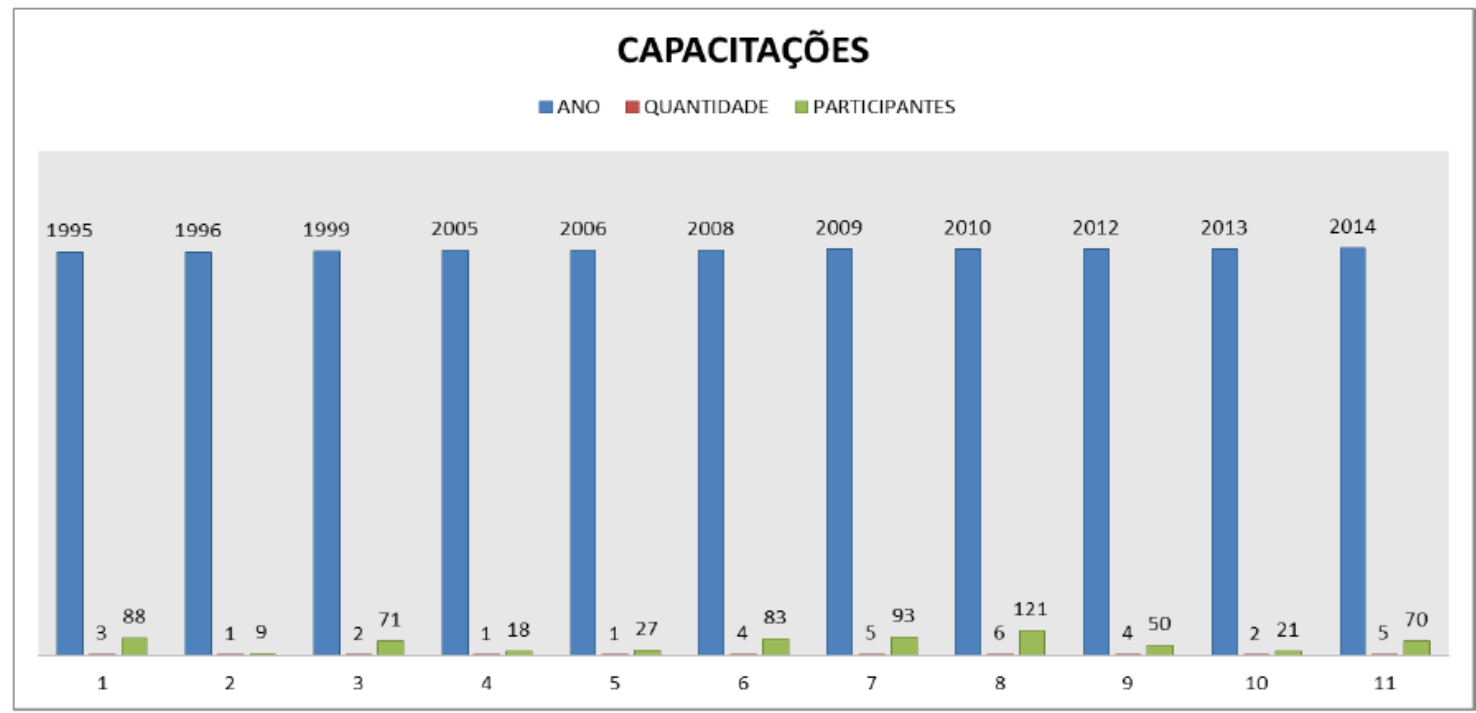

Fonte: Arquivos do Projeto de Extensão “Vamos amamentar, mamãe?”, 2014. 
Observa-se, a partir da llustração 5, que não foram encontrados registros da realização desta atividade entre os anos de 1997 a 1998, 2000 a 2004 e 2011. Destaca-se que os documentos existentes foram listas de frequência com o nome do curso que estava sendo ministrado, data e, em alguns o nome e assinatura de quem realizou a atividade. Dentre os temas abordados, o manejo clínico da amamentação foi o que mais constava nos registros.

Vale ressaltar que os profissionais de saúde devem estar preparados e capacitados no que se refere ao manejo clínico da amamentação, com intuito de promover a difusão de conhecimento técnico e científico em prol da promoção, proteção e apoio ao aleitamento materno.

Outros documentos encontrados foram cartilhas, diversos folders sejam para divulgação do projeto ou para direcionar o público alvo oficinas, cursos e treinamentos. Além disso, foram encontrados livros, textos xerocados de artigos e material informativo sobre as SMAM.

No que diz respeito à divulgação das ações do projeto e uma forma de melhorar a comunicação entre os integrantes, foram criadas uma página na web, a qual está sinalizada na cartilha educativa sobre amamentação. No Quadro 2, destacam-se as principais ações e documentos para auxiliar na divulgação do projeto e facilitar a comunicação entre integrantes. Apresenta ainda o ano de criação da primeira logomarca do projeto.

Nos dias atuais todo e qualquer assunto voltado em prol de benefícios para com a saúde da humanidade é sempre válida sua divulgação em todos os meios de comunicação, pensando assim, o projeto elaborou uma gama de materiais educativos durante esses 21 anos, que levaram e levam informações de maneira clara, objetiva e lúdica para uma boa assimilação do assunto e divulgação de suas atividades. Desta forma, caso alguém tenha dúvidas ou necessite de apoio para amamentar poderá entrar em contato com os integrantes para que possa ser direcionado alguém capacitado, a fim de esclarecer dúvidas, ou mesmo de cuidado mais específico, como cuidar de uma mama ingurgitada, realizar e orientar ordenha, colocar a criança na posição e pega corretas, dentre outras ações e cuidados.

Desse modo, foi possível perceber que as maneiras de documentação e atuação do projeto foram mudando com o tempo, sendo as capacitações e atualizações de fundamental importância para o melhoramento das ações desenvolvidas. A criação da página na web em 2012 foi um grande avanço para o grupo, pois possibilitou uma divulgação mais ampla do projeto, não se restringindo apenas a comunicação oral. Além disso, a criação do grupo em sites de relacionamento e aplicativos em smartfones facilitou muito a comunicação entre os integrantes. A primeira logomarca também foi um avanço já esperado há algum tempo, porque se pode utilizá-las como demonstrativo de identidade do grupo em palestras, oficinas, folders, banners e futuramente nas camisas personalizadas do projeto.

Estudo demostrou que as ferramentas nas mídias sociais podem ser aproveitadas para a divulgação do projeto de extensão e melhorar o seu impacto. Este resultado foi obtido com criação de Blog, ao obter 498 visitas de maio de 2011até agosto de 2011 de usuários do Brasil, Estados Unidos, Portugal, Alemanha, México, Rússia e Taiwan, mostrando que, uma informação que estava centrada e estática passa a ser compartilhada de modo rápido, ao ser mostrada demaneira mais atrativa e interativa, comprovando a importância das mídias sociais para o acesso à informação na área de Educação e Saúde ${ }^{14}$.

Entre as ações desenvolvidas durante os 21 anos de atuação do projeto, merece destaque os Encontros sobre aleitamento materno para proporcionar discussões atualizadas sobre a temática, tendo sido realizado o primeiro encontro em 1994 e o último em 2008, nos quais foram discutidas questões pertinentes às diversas subáreas da saúde, como enfermagem, medicina, odontologia, fisioterapia e nutrição. Destaca-se que os encontros não foram realizados de forma contínua devido às dificuldades enfrentadas pelos integrantes na realização dessa atividade, a saber, falta de recursos humanos, matérias e espaço físico.

Quadro 2 - Material de divulgação do projeto e comunicação entre os integrantes.

\begin{tabular}{|l|l|}
\hline TIPO & ANO DE CRIAÇ̃̃O \\
\hline Cartilha & 2003 \\
\hline Página na WEB & 2012 \\
\hline Grupo Facebook & 2013 \\
\hline Grupo Whatsapp & 2014 \\
\hline Criação Primeira Logomarca & 2012 \\
\hline
\end{tabular}

Fonte: Arquivos do Projeto de Extensão “Vamos amamentar, mamãe?”, 2014. 
Mesmo diante da grande demanda de participantes que ajudam na divulgação do projeto, a realização de eventos, como o encontro, ainda é a melhor maneira disseminar conhecimentos para um grupo maior de pessoas. Durante o desenvolvimento dos três eventos encontros, identificou-se a participação de um público significativo, inclusive em um deles com mais de 400 participantes. Portanto, são nestes eventos que se difundem não somente atualizações em aleitamento materno, mas, sobretudo, as atividades desenvolvidas pelos integrantes do projeto.

No que diz respeito às docentes que contribuíram para o desenvolvimento das ações do projeto, merecem destaque, as professoras do curso de enfermagem, com a colaboração de outros profissionais de saúde, como os fisioterapeutas.

Outras atividades desenvolvidas são: participação nas comemorações da SMAM, com distribuição de material educativo, divulgação na web a partir da página do projeto, entrevista em rádio FM da cidade, construção de murais educativos, envio de mala direta para os profissionais dos departamentos de saúde. Além disso, os integrantes vem participando de diversos eventos científicos, apresentando pesquisas sobre aleitamento materno que são desenvolvidas no âmbito das instituições em que o projeto atua. Os resultados destas pesquisas vem direcionando os integrantes do projeto a propor ações que visem a melhoria dos cuidados às famílias em processo de amamentação atendidas pelos membros do projeto.

Vale destacar que outras universidades do Brasil vem desenvolvendo projetos de extensão com vistas a promover, proteger e apoiar o aleitamento materno com ações única ou diversificadas, porém, esporádicas, com profissionais de diversas áreas de atuação ${ }^{15,16,17}$. Entretanto, nenhum deles tem um tempo de atuação como o Projeto de Extensão Vamos amamentar, mamãe?

\section{Dificuldades, facilidades e avanços do Projeto de Extensão “Vamos amamentar, mamãe?"}

As informações aqui apresentadas foram coletadas a partir dos relatórios das atividades desenvolvidas pelos integrantes do projeto. Assim, foi constatado que o projeto passou por dificuldades durante todos os anos de sua atuação. No entanto, houve facilidades e avanços que contribuíram para minimizar as dificuldades.

Dentre as facilidades destacam-se o compromisso e responsabilidade dos coordenadores, colaboradores e discentes bolsistas e voluntários, sem os quais não seria possível realizar as atividades propostas. Outra facilidade registrada nos relatórios diz respeito à utilização do transporte da UESB para locomoção dos discentes até a comunidade e Santa Casa para realização das visitas domiciliares e palestras educativas às puérperas e seus familiares.

Dentre as dificuldades descritas nos relatórios, a demora no repasse do material pela Gerência de Extensão e Assuntos Comunitários (GEAC) e liberação de autorizações para contratação de mão de obra de terceiros (álbum seriado e cartilha) foram as que mais se destacaram. A falta de recursos humanos (docentes), sobrecarga de trabalho da coordenadora e demais integrantes foi relatado em todos os documentos encontrados. A carga horária insuficiente para coordenar e realizar as atividades propostas deixam os profissionais estressados, desgastados e com pouca força para propor novas atividades já que este profissional também desenvolve atividades de ensino e pesquisa. A falta de espaço físico também foi listada como uma dificuldade, como uma sala própria para o projeto com armários, computadores, sala de reunião, dentre outras.

No que diz respeito aos avanços, merece destaque a inserção dos demais familiares nas atividades educativas e a inserção de discentes da Faculdade de Tecnologia e Ciências (FTC) como colaboradores externos e dos bolsistas de pesquisa. Outro avanço significativo foi a elaboração do projeto de pesquisa, do qual emergiram diversos estudos que estão sendo consumidos pelos integrantes do grupo, a fim de melhorar os cuidados prestados às famílias que vivenciam o aleitamento materno.

A criação dos canais de comunicação (facebook, whatsapp, e-mail do grupo) facilitou a união do grupo, proporcionando uma velocidade maior na comunicação, em especial na resolução dos problemas, como a ausência de um bolsista para realização de determinada atividade e a sua substituição de forma quase imediata.

Para divulgação do projeto em âmbito maior, a criação da página na web foi muito significativa, pois podemos divulgar de forma mais ampla como o projeto se organiza para desenvolver suas atividades, divulgar as atividades do grupo, estudos recentes sobre a amamentação, estudos produzidos pelo grupo, comemoração da SMAM, dentre outras atividades. 


\section{Conclusões}

A análise de documentos pertinentes ao desenvolvimento das atividades do projeto de extensão "Vamos amamentar, mamãe?" durante os vinte e um anos de sua atuação demonstrou o quanto ele vem contribuindo com as ações de promoção, proteção e apoio ao aleitamento materno na comunidade jequieense e cidades circunvizinhas. Dentre as ações desenvolvidas merece destaque aquelas que dependeram exclusivamente dos recursos humanos, como as atividades educativas individual e coletiva, as visitas domiciliares e capacitações em aleitamento materno.

A realização de treinamentos com profissionais de saúde, discentes universitários e da escola técnica de enfermagem foram importantes para capacitar os profissionais de saúde a atuarem de forma mais segura e eficiente no manejo clínico da amamentação.

Algumas das dificuldades foram superadas, outras impediram a realização de atividades essenciais ao andamento do projeto. Os integrantes do grupo tentaram driblar muitos dos obstáculos e, continuaram desenvolvendo as atividades possíveis. A falta de apoio institucional no que diz respeito ao provimento de materiais necessários ao bom desenvolvimento das ações foi um empecilho nos vinte e um anos de atuação do projeto.

Quanto às facilidades, uma das quais merece destaque foi a capacidade do grupo de seguir mesmo diante das dificuldades encontradas, o que pode ser demonstrado a partir dos avanços, em especial, a elaboração do projeto de pesquisa e o desenvolvimento de diversos sub-projetos, com resultados capazes contribuir para implementar e implantar cuidados sistematizados e individualizados às famílias que vivenciam o aleitamento materno.

Destaca-se que a interação entre as docentes e discentes do projeto com as puérperas e seus familiares, propiciou a troca de experiências, favorecendo o aprendizado e enriquecendo o processo educativo sobre a prática do aleitamento materno.

Sugere-se que os documentos continuem sendo organizados, pois um acervo tão importante como este não pode deixar de fazer parte da história de uma universidade pública que vem buscando integrar o ensino, a pesquisa e a extensão, pilares tão essências para o saber cientifico.

\section{Referências}

1. Santana JAT, Teixeira MA, Araújo RT. Projeto de Extensão Vamos Amamentar, Mamãe? In: SIGPROJ. 2013. Disponível em: http://sigproj1.mec.gov.br/projetos/imprimir.ph p ?modalidade $=0$ \&projeto_id $=102654$ \&local $=$ ho me\&modo=1\&original $=1$. Acesso em 01/12/2014.

2. Whaley LF, Wong DL. Enfermagem pediátrica: elementos essenciais à intervenção efetiva. 5 ed. Rio de Janeiro: Editora Guanabara; 1999.

3. Brasil. Ministério da Saúde. Secretaria de Atenção à Saúde. Departamento de Atenção Básica. Saúde da criança : aleitamento materno e alimentação complementar / Ministério da Saúde, Secretaria de Atenção à Saúde, Departamento de Atenção Básica. - 2. ed. Brasília : Ministério da Saúde, 2015. 184 p. : il. (Cadernos de Atenção Básica ; n. 23)

4. Word Health Organization. The optimal duration of exclusive breastfeeding: systematic review. Gene: who, 2001.

5. Fundo das Nações Unidas para a Infância - UNICEF. Declaração mundial sobre a sobrevivência, a proteção e o desenvolvimento da criança e plano de ação para implementação da declaração mundial sobre a sobrevivência, a proteção e o desenvolvimento da criança nos anos 90. Encontro Mundial da Cúpula pela Criança. Nações Unidas. Nova Yorque, setembro, 1990.

6. Magalhães MN, Lima ACP. Noções de Probabilidade e Estatística. São Paulo: Editora da Universidade de São Paulo; 2002.

7. Santos RV, Penna CMM. A educação em saúde como estratégia para o cuidado à gestante, puérpera e ao recém-nascido. Texto Contexto Enfermagem, 2009; 18(4): 652.

8. Rios, CTF, Vieira, NFC. Ações educativas no pré-natal: reflexão sobre a consulta de enfermagem como um espaço para educação em saúde. Ciência \& Saúde Coletiva. 2007; 12(2):477486.

9. Ferraz IS, Teixeira MA,Santos MB, Cruz LBS, Silva CT, Barreto CAS, Patrícia Paixão dos Santos PP, Silva SA,Erika RizSaldanha ERM,Almeida BRC. Educação em saúde sobre aleitamento materno no alojamento conjunto: relato de experiência. 20 Congresso Brasileiro de Política, Planejamento e Gestão em Saúde. Universalidade, igualdade e integralidade da saúde: um projeto possível. Belo Horizonte, 2013. 
10. Melo SN. Influência da assistência de enfermagem na prática da amamentação no puerpério imediato. Saúde em Debate. 2013; 37(96):130-138.

11. Demitto MO, Silva TC, Páschoa ARZ, Mathias TAF, Bercin LO. Orientações sobre amamentação na assistência pré-natal: uma revisão integrativa. Revista da Rede de Enfermagem do Nordeste-Rev Rene, 2009; 11:223-229.

12. Cordeiro TMSC, Filho VFM. Oficina sobre aleitamento materno: uma experiência exitosa num Hospital referência em gestação de alto risco. Ensino, Saúde e Ambiente. 2013; 6(3): 228240.

13. Delfino MRR, Patrício ZM, Martins AS, Silvério MR. O processo de cuidar participante com um grupo de gestantes: repercussões na saúde integral individual-coletiva. Ciência \& Saúde Coletiva. 2004; 9(4):1057-1066.

14. Andreetti TC, Anaruma SM. Mídias sociais e projetos de extensão: o aleitamento materno ao alcance de todos. 6o Congresso de Extensão Universitária da Unesp, 2011. Águas de Lindóia, SP. Anais eletrônico... PROEX/UNESP. ISSN no 2176-9761. p.0525. Disponível em: http://unesp.br/proex/congressos/6\%20congress o/fscommand/web/docs/0525.pdf. Acesso em 06/02/2017.

15. Agnol ACD, Busnello GF, Frigo J, Kolas M, Ascari RA, Zanotelli SS. Projeto de extensão promoção e incentivo ao aleitamento materno: um relato de experiência. UDESC em Ação. 2012; 6 (1). Disponível em: http://www.revistas.udesc.br/index.php/udesce macao/article/view/2454. Acesso em 06/02/2017.

16. Matos GC, Gonçalves KD, Cardoso QM, Soares MC SOARES, Borges ZS. Abordando o aleitamento materno em grupos de gestantes e puérperas: relato de experiência. XX Congresso de Iniciação Científica. III Mostra Científica. UFPEL, 2011. Disponivel em : www.abeneventos.com.br/anais_sben/74sben/p df/057.pdf. Acesso em 06/02/2017.

17. Alves e Lemes APM, Rosa JR, Borges JPA, Aquino LAM. Incentivo e promoção do aleitamento materno em um hospital universitário: vivências de um projeto de extensão. Em Extensão, Uberlândia.2014; 13 (2): 129-136.Disponível em: http://www.seer.ufu.br/index.php/revextensao/ article/view/27527/16087. Acesso em 06/02/2017.

\section{Endereço para Correspondência}

Universidade Estadual do Sudoeste da Bahia UESB

Av. José Moreira Sobrinho, s/n - Jequiezinho Jequié (BA)

CEP.: 45206-510

e-mail: marizete88@yahoo.com.br

Recebido em 14/06/2016

Aprovado em 09/03/2017

Publicado em 03/05/2017 